\title{
VEIDO REANIMACIJA PO VEIDINIO NERVO PAŽEIDIMO
}

\author{
Gabrielė Latakaitė ${ }^{1}$ Dainius Daunoravičius², Mindaugas Minderis ${ }^{3}$, Kęstutis Vitkus³, \\ Simonas Kaupas ${ }^{3}$ Rokas Bagdonas $^{4}$, Arnas Martinèlis ${ }^{5}$ \\ ${ }^{1}$ Vilniaus universiteto Medicinos fakultetas, ${ }^{2}$ Vilniaus miesto klinikine ligonine, \\ ${ }^{3}$ Vilniaus universiteto ligoninès Santaros kliniku Plastinès ir rekonstrukcinès chirurgijos centras, \\ ${ }^{4}$ Klaipedos respublikine ligonine, ${ }^{5}$ Lietuvos sveikatos mokslu universiteto Medicinos fakultetas
}

Raktažodžiai: rekonstrukcija, veidinis nervas, paliatyvus gydymas, transpozicija.

\begin{abstract}
Santrauka
Veidinio nervo pažeidimas sukelia ne tik funkcines, bet ir psichologines bei socialines problemas. Šiame straipsnyje pristatomas klinikinis atvejis: 54 metų moteriai dèl ilgalaikio veidinio nervo pažeidimo Vilniaus universitetinès ligoninès Santaros klinikos Plastinès ir rekonstrukcinès chirurgijos skyriuje 2015 metais buvo atlikta veido reanimacija, naudojant kramtomojo raumens transpoziciją ir plačiosios fascijos transplantaciją. Ivertintos priežastys, kreipimosi laikas po nervo pažeidimo iki rekonstrukcinio gydymo bei aptarti pooperaciniai rezultatai po pusès ir 2 metu pagal May klasifikaciją.
\end{abstract}

\section{Ivadas}

Veidinio nervo pažeidimas sukelia ne tik funkcinių, bet ir psichologinių bei socialinių problemų. Šis VII galvinis nervas yra mišrus: sudarytas tiek iš juntamujų, tiek iš parasimpatinių bei motorinių skaidulų [1], todèl svarbus palaikant veido tonusą, apsaugant aki (inervuojant m.orbicularis oculi), dalyvaujant artikuliacijoje bei judinant lūpas [2]. Taip pat reikšmingas įnervuojant mimikos raumenis, formuojant veido išraišką bei perduodant emocijas [3]. Sutrikus šioms funkcijoms, sukeliamas paciento nepasitenkinimas, kuris gali peraugti net ị socialinị atsiribojimą [2]. Todèl veido atkūrimas po veidinio nervo pažeidimo yra aktuali tema kiekvienam plastinès ir rekonstrukcinės chirurgijos gydytojui.

Veidinio nervo pažeidimas nustatomas 15-40 iš 100000 žmonių [4]. Jo priežastys gali būti ịvairios: apsigimimai (distrofiné miotomija, Mobius sindromas), traumos (kaukolès pamato lūžis, veido sužalojimai), infekcijos (encefalitas, vidurinès ausies uždegimas), neoplazijos (seilių liaukų navikas, veidinio nervo navikas), neurologinès patologijos
(Millar- Gubler sindromas), jatrogeninès (seilių liaukų ar mastoidito operacijos) ar idiopatinès (Belo paralyžius, amiloidozè, autoimuniniai sindromai) [5].

Pažeidus veidinį nervą jau per kelis mėnesius pradeda ryškèti veido horizontali ir vertikali asimetrija, atsiranda veido audinių pasmukimas [4]. Ypač daug problemų pacientams sukelia akių simptomai: lagoftalmas (kurio laiku neišsprendus vystosi keratitas ar galiausiai aklumas), ektropionas (sukeliantis akių ašarojimą). Dèl apatinès veido dalies paralyžiaus pacientams atsiranda seilètekis, kramtymo ir kalbejjimo sutrikimas[4]. Veidinio nervo jutiminių skaidulų pažeidimas sukelia skonio pakitimus.

Veidinio nervo funkciją atkuriančios operacijos technika pasirenkama priklausomai nuo VII nervo sužalojimo pobūdžio ir jo pažeidimo laiko [4]. Esant užsitęsusiam paralyžiui (ilgiau nei 1,5 metams) - pasirenkami aktyvūs (dinaminiai) ir pasyvūs (statiniai) rekonstrukcijos būdai. Pirmajam (judesio atkūrimui) - lūpos kampo pakèlimui, šypsenos simetriškumo atstatymui naudojama gretimojo raumens transpozicija (m.masseter arba m. temporalis) arba laisvo neurovaskuliarizuoto raumens persodinimas, o antrajam (statiniam) - veido audiniu pasmukimas koreguojamas naudojant plačiosios fascijos transplantatą, veido audinių patempimu ar sintetiniais tinkleliais bei siūlais.

Operacinė technika. Veido reanimacijos tikslas išspręsti

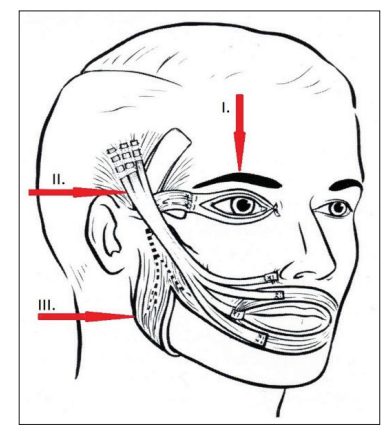

1 pieš. I - akis koreguojama taikant dalinę $\mathrm{m}$. temporalis fascijos transpoziciją; II - atstatant vertikalią veido asimetriją, naudojamas fascia lata transplantatas; III-atstatant horizontalią veido dalies asimetriją, atliekama m.masseter transpozicija. 
tris pagrindines problemas: akies (lagoftamo ir ektropiono ištaisymas), atstatyti horizontalią (lūpos kampo judesiai, šypsenos simetrizacija) bei vertikalią veido asimetriją (veido audinių pasmukimo atstatymas) (1 pieš.).

Akies problemos operacinis sprendimo tikslas yra apsaugoti akị, kuriai dèl paralyžiuoto $m$. orbicularis oculi ir atsiradusio lagoftalmo gali pasireikšti akių uždegiminès ligos. Pirmą kartą Ilig 1958 metais [7] aprašè svarelio implantaciją i viršutinį voką, o 1974 metais Jobe [7] išpopuliarino auksinio svarelio implantaciją, kuri tapo šiuo metu auksiniu standartu atmerktos akies gydymui.

Prieš operaciją pirmiausia svarbu ịvertinti būsimo implanto svorị. Tai atliekama priklijavus svarelị prie viršutinio voko centrinès dalies ir renkant tokị svorị, kad tarpas tarp abiejų vokų užsimerkus būtų ne didesnis kaip $1 \mathrm{~mm}$ [8]. Naudojama nuo 0,2 iki 1,4 g auksiniai svareliai, kurie fiksuojami prie m.levator palpebrea aponeurozès bei tarsus krašto.

Kita ir ne mažiau aktuali akies problema, kuri atsiranda pažeidus veidinị nervą, yra ektropionas. Apie jo operacinị gydymą pirmą kartą užsiminė Kirby 1953 metais [9]. O 1979 metais Anderson ir Gordy [10] pristatė operacinę techniką ektropiono gydymui - šoninę kantopeksiją (Lateral Tarsal -strip). Tai vienas iš standartinių metodų ektropionui

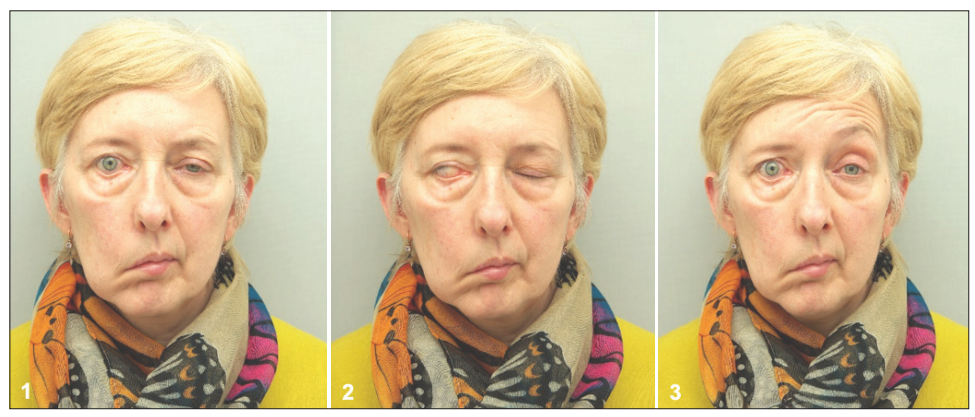

1, 2, 3 pav. Dešinès veido pusės pilnas paralyžius. Matoma ryški veido asimetrija (vertikalaus ir horizontalaus vektorių sąskaita), išlyginta dešinès pusės nazolabialinè raukšlè bei kaktos raukšlès dešinėje pusèje. Pažeistoje veido pusejje yra pasmukę žando audiniai bei lūpos kampas žemiau už sveikosios pusès. Nežymi antakių asimetrija kairiojo sąskaita. Diagnozuotas lagoftalmas ir ektropionas.

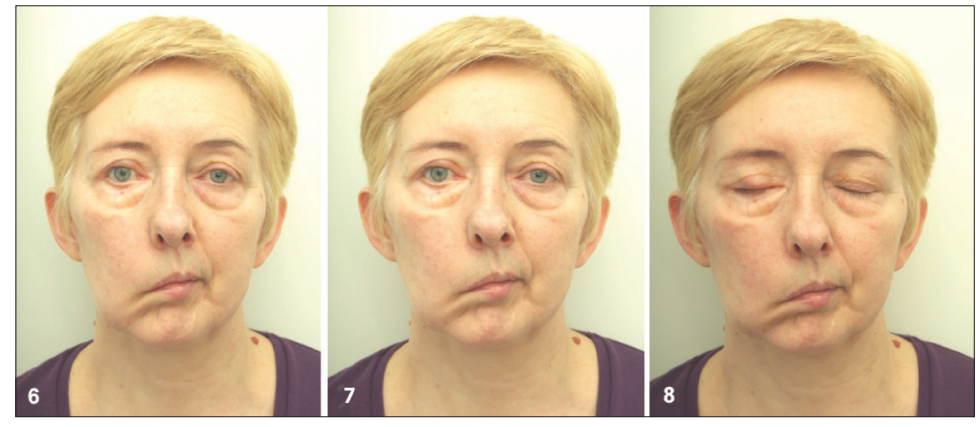

6, 7, 8 pav. Atliktas auksinio svarelio implantavimas ị viršutinị voką. Matomas pilnas akies užmerkimas. ištaisyti. Operacija atliekama, kai prakirpus voko lateralinį kampą ir nukirpus refraktorius iš voko kremzlès suformuojama $4 * 4 \mathrm{~mm}$ juostelè, kuri fiksuojama prie orbitos lateralinès sienos antkaulio.

Atkreipiamas dėmesys ir ị antakių simetriškumą. Pasmukusi antakị galima koreguoti tiesiogiai - ji pakeliant [10] (virš antakio atliekamas šeivos formos pjūvis ir eksizuojamas odos ir poodžio ruoželis) arba endoskopiškai. Pastarasis metodas yra populiaresnis, nes per 5 sagitalinius pjūvelius, atidalinant audinius palei antkauli ir atliekant aponeurozės duplikatūrą, antakis fiksuojamas naujoje pozicijoje [13].

Veido horizontaliojo ir vertikaliojo defekto gydymo tikslas - pakelti lūpos kampą, atstatyti lūpų kampo judrumą, atstatyti veido audinių pasmukimą. Mūsų klinikoje šiam tikslui buvo naudojama m. masseter transpozicija ir fascia lata transplantacija. Kramtomieji raumenys pirmą kartą veido reanimacijai panaudoti jau 1908 metais [5]. Tuomet

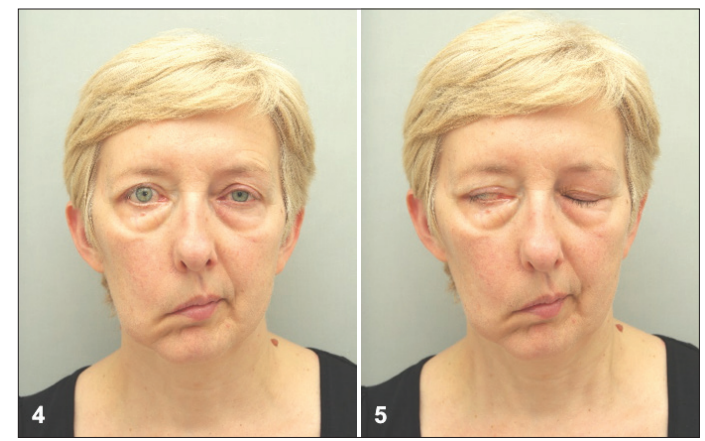

4, 5 pav. Atlikta lateralinè kantopeksija.

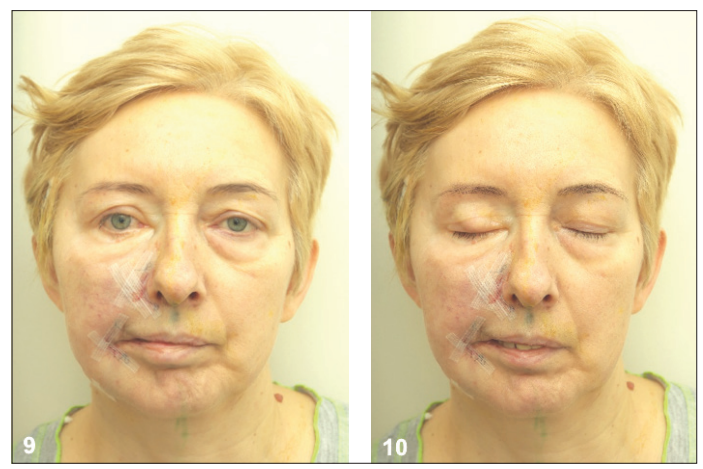

9, 10 pav. Pirma para po operacijos: minimali veido asimetrija, pakeltas lūpų ir nosies kampas, skruosto patinimas dešinèje pusèje. 
sekè daug modifikacijų, tačiau Conley ir Baker 1978 m. [5] pirmieji panaudojo kramtomaji raumenị reabilituojant apatinę ir vidurinę veido dali.

Šią operacinę techniką galima suskirstyti ị du etapus. Pirmasis - kai pjūvis atliekamas po apatinio žandikaulio viduriu ir pasluoksniui prieinama prie $m$. masseter, kurio priekinè pusè atjungiama nuo tvirtinimosi prie apatinio žandikaulio vietos ir pasukama link lūpos kampo. Pagal veido raukšlę padaromas antrasis pjūvis ir prieinama prie $m$. orbicularis oris. Atsukta m. masseter dalis ịskeliama per vidurị, kur padalintos šakos įkišamos ị abi lūpas ir prisiuvamos prie $m$. orbicularis oris. Antru etapu vertikalaus veido pasmukimo kompensavimui naudojamas pasyvus fascia lata autotransplantatas ( $2 \mathrm{~cm}$ pločio ir apie $17 \mathrm{~cm}$ ilgio juosta). Padalinus jo viršutinę dali i i 3 juosteles, jos ịpinamos ị smilkinio fasciją, o apatinè fascijos dalis padalinama ị 4 juosteles ir tunelizavus po skruostu, jos ịsiuvamos ị keturias vietas: lūpų kampą, abi lūpas ir nazolabialinị kampą.

Darbo tikslas: pristatyti klinikini atvejį, kai paliatyvaus veido paralyžiaus operaciniam gydymui buvo pasirinkta raumens transpozicija ir plačiosios fascijos transplantacija.

\section{Klinikinis atvejis}

Atvykusi 54 metų moteris skundèsi dešinès veido pusès paralyžiumi, deformacija bei pasmukimu. Liga prasidèjo 2009 metais, kai atsirado galvos svaigimas, pradejjo skaudèti dešinę veido pusę. Konsultuota Kauno klinikose, kur atlikus instrumentinius tyrimus, patologijos nestebeta ir paskirtas konservatyvus gydymas. 2011 metais atsirado dešinès pusès antakio, apatinio voko, skruosto nevalingi trūkčiojimai, ligonè pakartotinai kreipèsi ị Kauno klinikas. Atlikus magnetinio rezonanso tyrimą, įtarta ganglion geniculatum srities hemangioma. Tęstas stebejjimas. Po 2 metų instrumentinis tyrimas pakartotas (dinamikoje hemangioma nepadidejusi). Atlikus elektromiografinį tyrimą, nustatyta $n$. facialis 96
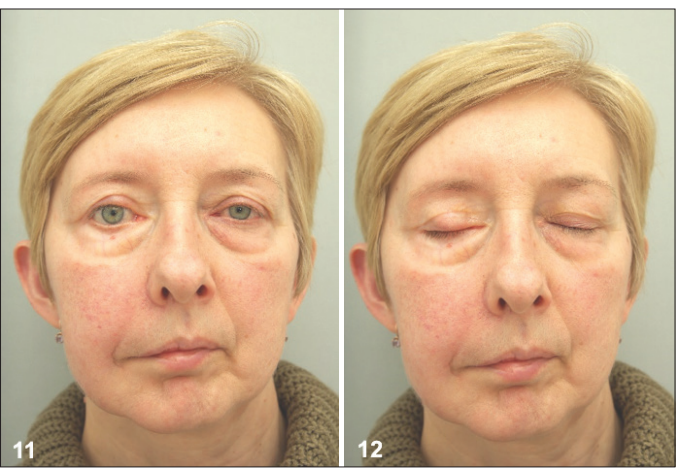

11, 12 pav. Pooperaciniai rezultatai po pusès metų: matoma nedidelè veido asimetrija, išlieka pakeltas lūpos kampas, susiformavusi nosies-lūpos raukšlè. proc. pažeidimas. Kreipimosi laikas nuo veidinio nervo pažeidimo iki apatinès veido dalies rekonstrukcijos 2 metai.

Objektyvaus ištyrimo metu diagnozuotas dešinès veido pusės pilnas paralyžius. Matoma ryški veido asimetrija (vertikalaus ir horizontalaus vektorių sąskaita), lygi dešinès pusès nazolabialinè raukšle bei kaktos raukšlès dešinejje puseje. Pažeistoje veido pusėje pasmukę žando audiniai bei lūpos kampas žemiau sveikosios pusès. Nežymi antakių asimetrija kairiojo sąskaita. Diagnozuojamas lagoftalmas ir ektropionas (1-3 pav.).

I chirurginiu etapu dèl dešinès akies ragenos erozijų, nuolatinių akies ašarojimų atlikta apatinio voko lateralinè kantopeksija (4-5 pav.), o po pusmečio taikytas auksinio svarelio implantavimas ị viršutinị voką. (6-8 pav.). II etapu - dešinès veido pusès rekonstrukcija, naudojant m.masseter transpoziciją, lūpų ir nosies kampo pakèlimą fascia lata transplantatu. Jau pirmą parą po operacijos buvo galima matyti minimalią veido asimetriją, pakeltą lūpų ir nosies kampą. (9-10 pav.).

Vertinant pooperacinius rezultatus po pusės metų: matoma nedidelè veido asimetrija, išlieka pakeltas lūpos kampas, susiformavusi nosies-lūpos raukšlè (11-12 pav.). Analizuojant po 2 metu, galima sakyti, kad rezultatai išlieka stabilūs: matoma nedidelè veido asimetrija, išlieka pakeltas lūpos kampas, susiformavusi nosies - lūpos raukšlè. Akis visiškai užsimerkia, o atsimerkus - stebima minimali asimetrija (13-14 pav.).

Todèl gydant akies, horizontaliosios ir vertikaliosios veido dalies defektą, naudojant $m$. masseter transpoziciją, fascia lata transplantaciją, auksino svarelio implantaciją ir lateralinę kantopeksiją, pagal May klasifikaciją [4] (1-2 lentelès), pooperacinius rezultatus galima ịvertinti kaip gerus.

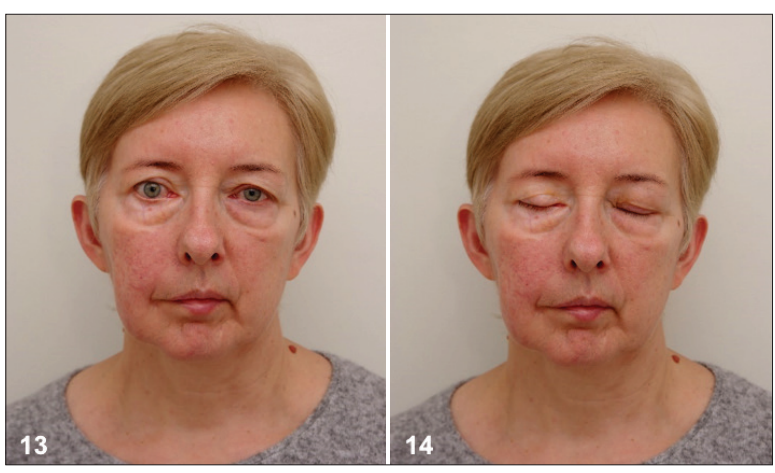

13, 14 pav. Pooperaciniai rezultatai po 2 metų - stabilūs rezultatai: matoma nedidelè veido asimetrija, išlieka pakeltas lūpos kampas, susiformavusi nosies - lūpos raukšlè. Akis visiškai užsimerkia, o atsimerkus - stebima minimali asimetrija. 
1 lentelè. May klasifikacija vertinant pooperacinius viršutinès veido dalies rezultatus.

\begin{tabular}{|l|l|}
\hline \multicolumn{2}{|l|}{ Viršutinės dalies pooperacinis vertinimas po rekonstrukcijos } \\
\hline puikūs & Akis visiškai užsimerkia ir nėa jokios asimetrijos \\
\hline geri & Nežymi asimetrija, nors ir visiškai užmerkta akis \\
\hline vidutiniški & Nėra skirtumo tarp abiejų atmerktų akių \\
\hline silpni & Asimetrija ar lagoftalmas, kai abi akys atmerktos \\
\hline
\end{tabular}

2 lentelè. May klasifikacija vertinant pooperacinius apatinės veido dalies rezultatus.

\begin{tabular}{|l|l|}
\hline \multicolumn{2}{|l|}{ Apatinès dalies pooperacinis vertinimas po rekonstrukcijos } \\
\hline puikūs & Jokio pastebimo skirtumo tarp abiejų pusių, juokiantis \\
\hline geri & Nežymi asimetrija juokiantis pažeistoje veido pusėje \\
\hline vidutiniški & Nėra skirtumo ramybės metu \\
\hline silpni & Asimetrija pažeistoje veido pusėje ramybès metu \\
\hline
\end{tabular}

\section{Diskusija}

Kai tiesioginès $n$. facialis neurorafijos ar nervo plastikos negalima atlikti dẻl nervo pažeidimo pobūdžio, jo vietos ar pažeidimo laiko, tuomet pasirenkami alternatyvūs veido rekonstrukcijos būdai [14]. Ilgalaikiam veido paralyžiaus gydymui gretimų raumenų pasukimas pasirenkamas tuomet, kai laikotarpis nuo pažeidimo iki operacijos yra užsitęsęs, atrofavęsi veidinio nervo ịnervuojamieji raumenys [15]. Populiariausias būdas šiai problemai spręsti - kramtomojo ar smilkininio raumenų transpozicija.

Smilkininio raumens panaudojimą veido apatinès dalies reanimacijai išpopuliarino Rubin, Barker ir Conley 1970 metais[4], tačiau daugelyje straipsnių apibūdinama, kad ši operacinè technika atkuria statinę burnos simetriją ir iš esmès pagerina judesių amplitudę šypsojimosi metu[16], bet sukelia deformaciją smilkininio raumens vietoje bei tinimą skruosto srityje [4]. Dèl to mes pasirinkome skelto kramtomojo raumens pasukimo ir plačiosios fascijos autotransplantato operacinę techniką.

Kramtomojo raumens transpozicija ir plačiosios fascijos autotranplantacija mūsų klinikiniu atveju davé gerus ir stabilius rezultatus po pusès ir po 2 metų kontrolès. Pirmasis plačiosios fascijos autotransplantato panaudojimą pradèjo naudoti Blair 1926 metais [17] ir išpopuliarino Freeman 1979 metais [17]. Autogeninis fascijos panaudojimas veido apatinès dalies rekonstrukcijoje turi privalumų, nes suteikia stiprų tempiamaji poveikị ir nesukelia jokios imunizacinès reakcijos. Jos analoginiai preparatai - aloplastinès medžiagos: Gore-Tex, Marlex tinklelis pasireiškia menku tempiamuoju poveikiu, granuliacijų susiformavimu, menki atmetimo požymiai bei niekada nepasižymi tokiomis savybemis kaip geras plačiosios fascijos integravimas ị savuosius audinius [17]. Kramtomojo raumens transpozicija leidžia atkurti fiziologinius burnos judesius, pagerinti išraišką ir artikuliaciją [4].

Mūsų pristatytame klinikiniame atvejyje akies problemai spręsti buvo pasirinkta auksinio svarelio implantacija ir lateralinè kantopeksija. Vertinant pagal May klasifikaciją, gauti geri ir stabilūs rezultatai: minimali asimetrija, nors ir akis visiškai užsimerkia. Literatūroje taip pat nurodoma, kad auksinio svarelio implantacija suteikia geriausius rezultatus, nes atkuria akies normalią funkciją ir neblokuoja matymo[15]. Neigiama pusè: be galimos infekcijos, atmetimo reakcijos, gali sukelti nepatogumų, diskomfortą užmerkus akị gulint [4]. Mūsų pristatytu atveju šio diskomforto ar komplikacijų po viršutinès dalies rekonstrukcijos pacientė nepažymėjo.

\section{Išvados}

1. Operacinè technika pasirenkama priklausomai nuo nervo pažeidimo lygio ir laiko.

2. Taikant kramtomojo raumens transpoziciją kartu su plačiosios fascijos transplantatu, gaunami geri rezultatai: atkuriamas veido simetriškumas, pakeliamas lūpos kampas, pagerinama išraiška ir artikuliacija, o naudojant auksini svareli ar lateralinę kantopeksiją apsaugoma akis.

3. Po veido rekonstrukcijos atkuriamas prarastas psichologinis bei socialinis paciento pasitenkinimas.

\section{Literatūra}

1. Budrys V. Klinikinė neurologija. Vilnius. Vaistų žinios, 2009; ISBN 9789955884248.

2. Fattah A, Borschel G, Manktelow R, Bezuhly M, Zuker R. Facial palsy and reconstruction. plastic and reconstructive surgery 2012;129(2):340e-352e.

3. Moore, Keith L., Dalley, Arthur F., Agur, Anne MR. Moore's clinical anatomy. United States of America: Lippincott Williams \& Wilkins, 2010; 843-980.

4. Kumral T, Uyar Y, Berkiten G, Mutlu A, Ataç E, Sünnetçi G. et al. How to rehabilitate long-term facial paralysis. Journal of Craniofacial Surgery 2015;26(3):831-835. https://doi.org/10.1097/SCS.0000000000001571

5. Kim J. Facial Nerve Paralysis. Medscape, 2014.

6. Crumley RL, Scott TA. Rehabilitation of facial paralysis. Otolaryngology-head and neck surgery, second edition, London, Mosby, 1993.

7. Terzis J, Kyere S. Experience with the gold weight and palpebral spring in the management of paralytic lagophthalmos. Plastic and Reconstructive Surgery 2008;121(3):806-815. https://doi.org/10.1097/01.prs.0000299919.18076.b4

8. Cordes S, Rassekh Ch. Reanimation of the paralyzed face. Dept. of Otolaryngology Grand Rounds 1998.

9. Kirby D. Surgical correction of spastic senile entropion: 
a new method*. American Journal of Ophthalmology 1953;36(10):1372-1380.

https://doi.org/10.1016/0002-9394(53)90795-8

10. Mohamed A. Marzouk, Ayman AS., Ehab SE., Tarek M., Elnaggar A. Lateral tarsal strip technique for correction of lower eye lid ectropion. Journal of American Science 2011; 7(5) 394-405.

11. Ritvik P, Mehta. Surgital treatment of facial paralysis. Clinic and experimental otorhinolaryngology 2009.

12. Core GB., Vasconez LO. Endoscopic browlift. Clinics in plastic surgery 1995 Oct;22(4):619-31.

13. Foustanos A. Suture fixation technique for endoscopic brow lift. In seminars in plastic surgery $2008 \mathrm{Feb} ; 22(1): 43$. Thieme Medical Publishers.

14. Baker DC, Conley J. Regional muscle transposition for rehabilitation of the paralyzed face. Clinics in plastic surgery 1979 Jul;6(3):317-31.

15. Lesavoy MA, Fan KL, Goldberg AG, Dickinson BP, Herrera F. Facial reanimation by staged, split masseter muscle transfer. Annals of plastic surgery 2014 Jul 1;73(1):33-8. https://doi.org/10.1097/SAP.0b013e31826cb267

16. Michaelidou M, Tzou CH, Gerber H, Stüssi E, Mittlböck M, Frey M. The combination of muscle transpositions and static procedures for reconstruction in the paralyzed face of the patient with limited life expectancy or who is not a candidate for free muscle transfer. Plastic and reconstructive surgery 2009 Jan $1 ; 123(1): 121-9$
https://doi.org/10.1097/PRS.0b013e3181904cff

17. Rose EH. Autogenous fascia lata grafts: clinical applications in reanimation of the totally or partially paralyzed face. Plastic and reconstructive surgery 2005 Jul 1;116(1):20-32.

https://doi.org/10.1097/01.PRS.0000169685.54862.18

\section{FACE REANIMATION AFTER FACIAL \\ NERVE INJURY}

\section{G.Latakaitė, D.Daunoravičius, M.Minderis, K.Vitkus,} S.Kaupas, R.Bagdonas, A.Martinèlis

Key words: reconstruction, facial nerve, palliative treatment, transposition.

Summary

Facial nerve damage causes not only functional but also provides psychological and social problems. This article presents clinical case of patient who has been made facial reanimation used by masseter muscle transposition and fascia lata transplantation after long-term facial nerve damage in Plastic and reconstruction center of Vilnius university hospital Santaros clinic 2015 years. Assessed reasons of facial nerve damage, time between facial nerve palsy and reconstruction treatment. Analyzed post-operative outcomes according to May classification after half and two years.

Correspondence to: latakaite.gabriele@gmail.com

Gauta 2018-04-21 